\title{
SMCP Development for Pilotage and Tug Assistance in the light of Diffusion of Innovations Theory
}

\section{Adelija Čulić-Viskota}

This paper is based in part on an earlier publication ${ }^{1}$ on SMCP development, but includes new chapters on sociolinguistic and cultural issues arising during pilot's taking the vessel into/ out of harbour with tug assistance. In this case the multinational, multilingual and multicultural bridge team is further extended onto pilot/s communicating with the tug master(s). A request has been made by the IFSMA ${ }^{2}$ to provide shipmasters with a set of phrases for pilots and tug masters in their working language - English - to be used during manoeuvring, since the existing Standard Marine Communication Phrases (SMCP) have not been considered elaborate enough for the operation. Maritime English lecturers twinned with maritime professionals have provided a set of appropriate phrases and exercises to help students/ trainees adopt them, as the conclusion of the 2014 seminar organized by G.A.M.E. - Gesellschaft für Ausbildung in Maritimem Englisch (German Association for Maritime English) with the seat at Bremen University of Applied Sciences, Nautical Department, in order to meet the requirements from the maritime industry.

\section{KEY WORDS}

$\sim$ ESP

$\sim$ Maritime English

$\sim$ SMCP

$\sim$ Pilotage

$\sim$ Tug assistance

$\sim$ G.A.M.E.

University of Split, Faculty of Maritime Studies, Split, Croatia

e-mail: adelija.culic.viskota@pfst.hr
A sociolinguistic and cultural issue has arisen as a result of the IFSMA's invitation to G.A.M.E for a further development of the SMCP Pilotage and Tug Assistance Phrases and for presentation of the newly developed phrases for assessment to the IMO as a most influential safety factor. It would be a great benefit for shipmasters worldwide who regularly find themselves in situations when they cannot follow the pilot's communication with the tug master(s) because it is carried out in a local language and the pilot, due to being involved in communication with several external parties, is often not in the position to translate the communication for the ship's master due to the shortage of time. This intention of the IFSMA has met an overt disagreement by the pilot representatives taking part in the activities of the 2014 G.A.M.E. seminar and previously by the EMPA as their association. Therefore, following the approach starting from Rogers' Diffusion of innovations theory (1960), revised later by Clarke (1999) and Orr (2003), is proposed here to present the stages through which a technological innovation, this extension of SMCP being rightfully considered one, passes on its way to successful adoption.

\section{INTRODUCTION}

The world's oceans present no borders. Likewise, ships have long been manned with crews gathered internationally. Among the early examples of this practice is Magellan's Spanish

1. Čulić-Viskota, A., Essential English for Pilotage and Tug Assistance - Proposal for SMCP Extension, ToMS, Vol.03, No.02, October 2014, pp. 158-164.

2. IFSMA Res. 1/2012 (AGA 38), Further Development of SMCP (Standard Marine Communication Phrases). 
expedition, his fleet consisting of a culturally diverse crew of Spaniards and Portuguese as a vast majority of the sailors, but also of mariners from Greece, Sicily, England, France, Germany and even North Africa ${ }^{3}$. Surprisingly, there were even Basques among the crew. De Borja (2005: 10) provides the following information: "The list of Basques involved in the preparation and manning of the expedition was notable.... Of the 275 men who made up the crew of the expedition, at least 35, or 12.7 percent, were Basques."... "Second, members of the multinational crew, particularly the Spaniards, were hostile toward Magellan." (ibid.) ... "On February 13, 1522, Elcano, together with a crew of forty-six Europeans and nineteen Malays, left the island of Timor to head back home." (2005:12). Another, more recent example is Thor Heyerdahl. "He was also a fervent internationalist; his crew was always multinational and his boats flew the UN flag."4 Since early vessels crossed a body of water either for conquest or trade, possibilities have been arising for mixed crews.

Nowadays, shipping is one of the most integrated industries in the world economy and major means of transport (Ljung, 2010; Gekara, 2008), in which about $70-80 \%$ of the world's merchant fleet has multicultural crews (Magramo and Cellada, 2009; Pyne and Koester, 2005). The vast majority of modern ships can be considered as meeting points of representatives of different cultures gathered to form a working team with the purpose of reaching the common aim of making profit for themselves and their employers.

In this paper, the navigating team gathered on the navigating bridge of a ship during pilot's assistance in manoeuvring the ship to her berth or when leaving berth, often calling for assistance of harbour tugs will be considered from the sociolinguistic aspect, i.e. the relationship between language and society, which can help uncover the social relationships within a community. In most cases, the above mentioned situation involves individuals of different nationalities and native languages meeting in their social working environment. In this case it is the bridge team, already multinational and using English as occupational language, extended onto the pilot(s) and tug master(s), speaking usually the same local language(s), the former most often with high proficiency in English, especially Maritime English, and the latter usually expecting the communication with the pilot(s) to be carried out in the local language, but being increasingly aware of the need to master Maritime English, especially in ports with heavy international traffic. Since nationality and language are cultural components, their expressions by the pilots and tug masters tend to be deeply rooted as local customs and retained due to the capacity of providing them with power at the local level, while the linguistic diversities within this extended bridge

3. source: http://www.history.com/news/history-lists/10-surprising-facts-aboutmagellans-circumnavigation-of-the-globe (accessed: October 5, 2014).

4. source: Lonely Planet Norway, by Anthony Ham, Stuart Butler, Miles Roddis, Lonely Planet, August 1, 2011, p. 132 (accessed: October 5, 2014). team, on the other hand, can easily lead to misunderstandings, poor communication and maritime accidents.

The development of the set of Standard Marine Communication Phrases (SMCP) with particular emphasis on the operations of pilotage and tug assistance ${ }^{5}$ has already been reported as crucial for the circumstances in which the bridge team is extended to parties external to the ship's crew and speaking a different common language. The multilingual issues that have arisen are taken into consideration from the sociolinguistic and cultural point of view.

Maritime lecturers are also considering possible ways of implementing the new phrases into the existing syllabi for Maritime English courses at higher-education institutions through the development of new exercises to accompany the phrases developed.

However, the implementation of the phrases into university Maritime English syllabi is not in itself a guarantee of their full implementation for the reasons discussed in the following chapters. A large number of innovations are opposed at the very attempt of their being brought into life for a variety of reasons. In many cases it is the fear of something new, unknown and its possible adverse effect on the existing state of affairs. This fear is largely overcome with the passing of time and the end users of innovation gain consciousness of its usefulness and the benefits it brings along. Another possible reason for opposing an innovation is an anticipation of the loss it can bring about to part of the participants in the process without regarding the benefits it brings to the other party/-s involved in the process. This situation is for obvious reasons more intricate to deal with and calls for subtle methods after an initial analysis of the actual pros and cons. This is the reason for attempting to see the issue in the light of Diffusion of Innovations theory applied to SMCP Pilotage and Tug Assistance phrases with a view to a future more consistent implementation of SMCP as working code.

\section{CULTURE / MULTICULTURALISM / INTERCULTURALITY}

Culture is defined in many different ways with reference to its different aspects. The term has originated from the Latin noun cultura, ae f. derived from the verb colo,3. colui, cultum = to cultivate (land), to take care of, to respect, to honour. The concept was already used in ancient times by Cicero referring to "cultura animi" implying an abstract concept. It was later re-established in the $17^{\text {th }} \mathrm{ct}$. Europe with the meaning of personal refinement, mostly through education. In the following centuries the original metaphorical meaning was disregarded, as well as the relation between culture and nature that was so important in the Roman

5. For further details see: Čulić-Viskota, A.(2014).

4. “Cultura autem animi philosophia est; ..." in Cicero's Tusculan Disputations, Book Two - On Bearing Pain. 
times, and culture began to be conceived of as a common reference point of different peoples or as a universal human capacity of refinement of the mind. The $20^{\text {th }} \mathrm{ct}$. saw culture as an umbrella concept implying a range of human traits not directly attributable to genetics only. In the anthropological sense culture means a diversity of learned human behaviour patterns ${ }^{7}$, providing persons with the capacity to use them imaginatively and creatively, and also the capacity related to different ways in which people process, classify and represent their experiences and ultimately act creatively. Thus, Hoebel designates culture as "the learned behaviour in its aggregate" or "the integrated sum total of learned behaviour patterns which are manifested and shared by the members of a society". (Hoebel, 1954: 7) He also points out that "man alone has culture-producing and culture-maintaining capacities" and that "man alone can convey learned behaviour through speech." (ibid.) Thus, culture is passed on from generation to generation by learning and once adopted it becomes habitual or "natural". So, the relatedness of culture to human behaviour can be compared to the relatedness of grammar to a language. They both determine the user's position and relations within an environment or system, the former in the social, the latter in linguistic sense. Just as it is the case with language, being itself part of culture, culture determines our worldview, the way in which we view, experience and interact with different aspects of the world around us. At this point, the concept of cultural invention should also be introduced, just as new terms are introduced into a language to denote previously unknown concepts or objects. It can mean any innovation thought to be useful to a group of people to express their behaviour. Cultural innovations also strive to achieve their appropriate positions. There are always forces in favour of changes and those opposing them. These forces depend upon the substance of which current structures are made: the more resilient ones will insist on the preservation of cultural practices within the current conditions; still, these structures themselves are likely to undergo changes. Therefore, new cultural models sometimes have to wait for changes to happen first within the society in order for an evolutionary action to start. Different experiences can also emerge from and be perceived through contacts with representatives of different cultures, i.e. in multicultural environments. Multiculturalism is rather a descriptive term implying the coexistence or simultaneous existence of two or more cultures in the same environment. It refers to the factual state of affairs without further particulars. Inter-culturality or cross-culturality implies interaction between/among coexisting cultures, i.e. their representatives, in our case seafarers as members of multinational crews. This can

7. The term was first used in this way by the pioneer English anthropologist Edward B. Tylor in his book, Primitive Culture, published in 1871. Tylor defines culture as "that complex whole which includes knowledge, belief, art, law, morals, custom, and any other capabilities and habits acquired by man as a member of society." be referred to as acculturation, or replacement of the traits of one culture with those of another, either at individual or group level. Changes in cultural practices can be influenced by contacts between/among societies at a particular point in time, which may encourage or impair the changes. This is exactly what the pilotage-and-tug-assistance situation implies: there are at least two, sometimes even three, languages involved in the operation which calls for being conducted in one language only so that the communication becomes legible to all the participants. The language proposed by the shipmasters and opposed by the pilots and part of the tug masters is English, as the occupational language in maritime affairs in general. The whole setting in which the local language is used instead of the working language in order to preserve the roles of the local participants in the scene is a form of cultural event. The participants are striving to preserve the linguistic (cultural) relations as they currently are in order not to be deprived by any chance of their importance in a future, possibly altered scene. Thus, striving to preserve the use of the local language in this specific kind of setting means preserving cultural pragmatics in favour of the local culture in which pilots and tug masters have always communicated in the local language without an insight into other participants' needs.

\subsection{Multinational / -Cultural / -Lingual Aspect of Ship's Bridge Team}

It has become clear to shipping company managements that efforts have to be made to raise the level of cultural awareness with their employees since seafarers' education worldwide is still rather poor as far as cross-cultural communication is concerned. So, shipping companies invest their knowledge and effort to make their shore-based and on-board staff culturally aware. Thus, in 2007 the Japanese shipping company NYK informed about a research which involved all of their employees originating from different cultures and resulted in the Guidelines for intercultural relations, i.e. a circular sent to the masters of NYK-owned ships with the following note: "It is hoped that these Guidelines' readers will have the awareness in breaking the barriers, deterring misconception and misjudgement against certain cultures that may hinder a productive relationship on board ship; and for a greater number of our people to feel greater satisfaction and enjoyment because of an enhanced good working relationship in any ship." It was recommended to provide a copy of the circular in the mess halls and other conspicuous areas on board to serve its purpose. ${ }^{8}$ In short, the Guidelines consisted of three parts: Part One, focused on explaining the notion of intercultural relations, on looking for similarities rather than differences, on learning

8. For details, see: Culic-Viskota, A \& Bielic, T., Cultural and linguistic differences as factors of ineffective communication, IMEC-19 Proceedings, Rotterdam, October 9-12, 2007. 
about differences as enriching and exciting experience, on falling into the trap of generalisations or cultural stereotypes but the emphasis was always put on good will, care for whom/ what is different, showing interest and tolerance. Part Two, called Practice Cultural Sensitivity, is based on the idea that each person is unique despite his/her belonging to a certain group that may be characterized by set stereotypes. Therefore, what is of utmost importance is the awareness that differences of opinions and beliefs should be expected and consideration and respect should guide a person's behaviour. The remaining part of the Guidelines is dedicated to particular cultures whose representatives are most usually found on board NYK Company ships and each chapter is divided into Do's, Dont's and Things to remember when with... But, special attention was paid to the attempt of explaining certain basic notions of Chinese culture which correspond to the notion of face in western cultures ${ }^{9}$, related to politeness in communication. So, an attempt was made at both theoretical and practical explanations of how cultures in contact work, in order to raise the level of self-awareness in the context of one's own culture as well as awareness of the existence of other, different cultures deserving respect and tolerance. Other attempts in the field of maritime affairs followed, both by the International Maritime Organisation and shipping companies as well as by maritime departments at universities worldwide. ${ }^{10}$ All of the studies mentioned are focused on the significance of multicultural awareness, intercultural relationships on board vessels and implementation of multicultural contents into maritime education and training.

\subsection{English-Language Bias as a Cultural Issue}

With all the praiseworthy initiatives to establish and preserve cultural differences on board ships, Maritime English,

9. The term was first introduced by Erving Goffman (1959) when referring to human relationships in everyday life. It was later elaborated on by Brown \& Levinson (1987) in their account of developing strategies of polite communication. (for more, see Culic-Viskota,A.\& Bielic,T. (2007:29).

10. Jenni Storgård, Nora Berg \& Olli-Pekka Brunila in their "Insight in Ship Crews - Multiculturalism and Maritime Safety", Centre for Maritime Studies, Univ. of Turku, Finland, IMISS, June 12, 2013, take into account 18 previous studies related to multiculturalism and maritime safety. Another important study carried out at Constanta Maritime University is Chirea-Ungureanu,C. \& Raluca Vişan, I., Teaching Communication Skills as a Prerequisite of the Course on "Intercultural Communication Onboard Ships" presented at the International Conference IMLA-19, Opatija 2011. Also, KNOW-ME, The European Academic and Industry Network for Innovative Maritime Training, Education and R\&D project has resulted in different maritime e-courses of 45-hour duration that can be started any time when one is online and among which there is also Cross-Cultural Training. All courses are intended for potential and current workforce onboard and onshore, employees in the maritime industry. The course has been developed by Dorina Pörksen, qualified industrial engineer of maritime transport, whose diploma thesis was part of a project funded by the European Commission with a research focus on cultural diversity on board and the development of cross-cultural competences of future seafarers.. a form of ESP, is the working language in shipping. ${ }^{11}$ Maritime English is deeply rooted in centuries-long British seafaring tradition which has established it as a proper worldwiderecognized seafaring jargon. As Crystal (2003: 106) points out: "English has long been recognized as the international language of the sea, and in recent years there have been attempts to refine its use to make it as efficient as possible. Larger and faster ships pose greater navigational hazards. Shipping routes continually alter and present fresh problems of traffic flow. Radio and satellite systems have greatly extended a ship's communicative range. In such circumstances, mariners need to make their speech clear and unambiguous, to reduce the possibility of confusion in the sending and receiving of messages."12

It is a well-known fact that English is also the working language in aviation but in this branch it has been fully adopted and no other language is used for communication, not even in situations when pilots and air-traffic controllers speak the same language. This state of affairs has followed from several plane accidents resulting from communication failures.

On this basis there have been attempts to set up the minimum language proficiency requirements for members of ships' crews as well. Moreover, a study ${ }^{13}$ on actual maritime language proficiency level was carried out through collaboration of several leading maritime education and training institutions in the EU as it had been found out that English language skills of the ships' crews were at a very low level, resulting in ineffective communication and this ineffective communication was the major cause of many accidents. The study included 64 lecturers and professors and more than 30 maritime academies and universities worldwide. The results of the questionnaire about their students' proficiency level showed that $41 \%$ of the students were at B1 Intermediate level, $34 \%$ at B2 Upper Intermediate level but $24 \%$ were at A1 Beginner and A2 Elementary levels, which is utterly unacceptable. On the other hand, SOLAS (Safety of Life at Sea) Convention still allows in Chapter V: Safety of Navigation, Regulation 14 (4): "English should be the working language ... for the bridge, bridge-to-bridge or shore and on board for the communication between the pilot and the bridge watch-keeping personnel ... unless those directly involved in the communication speak a common language other than English." Thus, there seem to be apparently contrary forces at work: those promoting the use of an internationally-agreed working or occupational language for on-board use in all circumstances with the clear objective of raising safety through simple and unambiguous communication,

11. More about Maritime English in: Culic-Viskota, A., Kalebota,S.,(2013) Maritime English - What Does It Communicate", ToMS, Oct.2013, Vol.2,No.4,ISSN 18483305, pp.109-114.

12. Emphasis added by Čulić-Viskota, A.

13. "Captains Project - Communication and Practical Training Applied in Nautical Studies" (2010-2012) finalized and available at: www.captains.pro. , accessed on (April 21, 2015). 
and those insisting on retaining culture-specific traits of the participants in maritime affairs, their native and local languages being obvious examples of those traits. Yet, however hard it might sometimes be to separate the personal from the public, individual or partial from common, maximum effort should be invested in cases where it contributes to raising the level of safety for all the involved alike.

\subsection{Specific Language/Cultural Requirements in Pilotage and Tug Assistance}

The ship's master, pilot and tug master represent the three pivots in conducting the ship to her berth or seeing her out when she is leaving it, and communication between them should be clear and unequivocal. The ship's master may, of course, decide to rely completely on the pilot's competency, but he should definitely be given the chance to decide so on his/her own by being able to follow the pilot's communication with the external parties, especially with the tug master(s).

In the paper cited above ${ }^{[1]}$ an example is presented of Capt. Eric Blom's ${ }^{14}$ experience. He describes the situation in which his helm orders had to be translated into three different languages before they were executed by the helmsman and where establishing a closed loop ${ }^{15}$ was a real challenge. Therefore, Capt. Blom insists on the importance of effective communication among the bridge team members using one instrument only, i.e. Maritime English.

Cultural differences should also be taken into consideration as they often combine with deficient knowledge or total inability to conduct communication in English. Thus, to relate this issue to Hofstede's cultural dimensions, here we can observe numerous situations where cultural predisposition towards leadership and authority emerges. Namely, the pilot is perceived as an authority whose decisions in many cultures it is difficult to correct or even question. This may mean that correction of errors may therefore not be made in time or suggested at all. A number of maritime accidents have occurred exactly due to this reluctance to interfere. ${ }^{16}$ This, obviously, also applies to tug assistance and the relative communication, which should be conducted in a language common to all the parties involved to minimize the possibility of communication failure. In case the pilot speaks in a language which is not understood by the master, it makes it

14. Capt. Erik Blom, Master of the M/V BLACK WATCH, Fred. Olsen Cruise Lines, entitled "Is the pilot a part of the bridge team?".

15. The "closed loop" is a communication protocol where information is given, repeated by the receiver and normally confirmed by the issuer. This is the only way one can be sure an order is being followed and is a vital part of the bridge team management.

16. This reluctance to interfere with whom is considered an authority is referred to as leadership complacency (more in: Bielić, T., Complacency as Element Influencing Ship Accidents, Naše more 51(3-4)/2004, pp.89-95). difficult for the master to develop situational awareness.

An enhanced form of SMCP Chapter on Pilotage and Tug Assistance can help to avoid language difficulties leading to accidents.

Capt. Meyer's ${ }^{17}$ draft version of extended SMCP for pilotage and tug assistance, revised during the 2013 Bremen workshop after having consulted the work done by some of the former contributors to this specific field such as: Capt. Brooks and Capt. Schisler from the USA, Capt. Michael Kelly, Sydney Pilot, Capt. Peter Liley from Brisbane, Capt. Cerwyn Phillips, Pilotage Operations Manager, Port of London Authority, and taken into consideration the contributions from pilots in Los Angeles and Rotterdam was subsequently discussed with pilots from the ports of Bremerhaven and Hamburg to round up the picture of their needs during pilotage and tug assistance in order to be able to contribute to a further development and curricular implementation of the SMCP chapter extended. It was at this point that the participants of the G.A.M.E. seminar were faced with an overt disapproval of the extension of SMCP to cover their activities in English, especially of the possible mandatory use of English for communication serving piloting and tug assistance during manoeuvring when the parties involved do not share the same native language. The pilots made efforts to convince the lecturers that it was impossible for them to use English for communication during the above mentioned manoeuvres. Their view of the current issue was also supported by a former Chief Pilot in the port of Split, Croatia ${ }^{18}$. Among the reasons presented were:

1. Harbour tug assistance has more than a long tradition and, as regards safety of manoeuvring with tug assistance, the current mode of operation (i.e. communication between the pilot and the tug master(s) in their mother tongue) has been established for a very long time.

2. The Master of the assisted vessel was always in the position to follow what the tug was doing, although he sometimes did not understand the language of communication. Namely, by seeing the tug taking a certain position, by seeing the propeller thrust astern of the tug, by seeing the load in the towing line, if or how much slack there is in it, etc., the Master could follow what was happening and possibly make a remark, if he is not satisfied.

3. If in the future we force the pilots and tug masters to use for mutual communication a foreign, in this case the English language, we would, especially in the beginning, have difficulties in adaptation, with possible harmful consequences.

4. Very little, almost nothing is gained by the ship's master by hearing a command that he can understand because most often,

17. Capt. Matthias Meyer is a full member of G.A.M.E. and the principal author of the extended SMCP for Pilotage and Tug Assistance (for more see: ČulićViskota, A., Essential English for Pilotage and Tug Assistance - Proposal for SMCP Extension, ToMS, Vol.03, No.02, October 2014, pp. 158-164.).

18. Author's personal communication. 
before he sees the consequence of the new command, he will not make an objection anyway.

5. The alleged concern to ensure better safety masks the tendency for the ship master to be more actively involved in the realisation of all the tug/s-related actions so that the ship masters worldwide do not require pilot assistance (as pilots have always communicated with tug masters in their own mother tongue) but are able to work on their own, without pilot assistance during manoeuvring in port, even in case when tug assistance is required.

From the above presented reasons the underlined parts unveil many facts that can be brought down to cultural issues. Namely, the statement in 1) could be rephrased as "disrupting the status quo can disrupt people's comfort level". The pilots feel comfortable the way manoeuvres are currently carried out and they could not put themselves in the position of the ship's master who would actually benefit from the mandatory use of English. The statement in 2) shows a degree of allowance for the ship's master but an effort from his side to understand what is being done with the ship he/she commands is considered acceptable by the pilots. The statement in 3) brings about a dose of concern with possible effects of the mandatory introduction of English as if subtle spreading of concern was expected to arouse with lecturers concern about their possible responsibility in case an accident happens due to enforcing the communication in English. In 4) there is an obvious attempt to present a presupposition as an argument, while in 5) there is finally the fear expressed for possibly being disarmed of the local language tool which in this context represents power, and power ensures existence, both financial and social. This could be represented as follows:

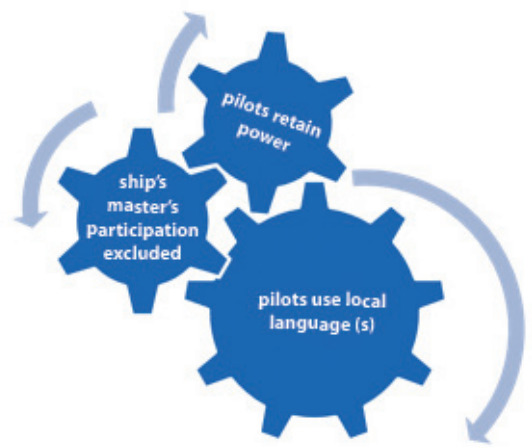

Figure 1.

Language as power.
Therefore, from the cultural point of view it has to be taken into consideration that cultural changes take time to root, and pilot's and tug master's switching to a foreign language even if occupational and however functional, can definitely be considered one, since so far they have been used to making use of their common native language even in cases when the bridge team members are of different native languages and use English for on-board communication. The exception to this practice is the pilot - master exchange of information, but in the occasions when the pilot hardly finds enough time to translate commands to the ship master, the latter remains an outsider. When no problems arise during manoeuvring, the master can be said to be relieved in a way by the presence of the pilot and due to the reliability of his knowledge and skills, but when things go wrong, it is always the master to take the blame. Therefore, this initiative of the IFSMA for the development of elaborate set of phrases in English to be used during pilotage and tug assistance is entirely justified.

From the sociolinguistic point of view, i.e. the point of view of the influence of language on society, it is vital to gain consciousness of the role that knowledge of a language and sharing it with the local community usually has. As Angela Carter, $20^{\text {th }}$-ct. British journalist and writer, said: "Language is power, life and the instrument of culture, the instrument of domination and liberation." In this sense, the opposition of pilots and tug masters to the implementation of English-biased communication among the extended bridge team members during pilotage and tug assistance is entirely understandable. People readily reject giving up weapons that can ensure their survival, and language can in many occasions be regarded as such powerful weapon. In this case it undoubtedly preserves their positions in the current state of affairs and ensures their domination. On the other hand, introduction of English-biased communication during pilotage and tug assistance would mean liberation for the ship masters, who would feel relieved by the possibility of understanding what is going to be undertaken with regard to his/her vessel without dependence on the pilot's translation, which sometimes misses due to his being burdened with his own, complex enough responsibilities.

Thus, striving of pilots to retain their current position in the state of affairs by not being in favour of changes obviously beneficial for the other party involved, i.e. ship masters, has obvious influence on language, more precisely occupational language or jargon pragmatics. 


\section{DIFFUSION OF INNOVATIONS (DOI) THEORY'19}

A whole theory has been developed under the name of Diffusion of innovations theory dealing with the conditions to meet in order for new ideas, products or practices to be adopted. According to this model based on research carried out in the fields of anthropology, sociology and education Dol was developed by Everett Rogers, a sociologist and professor in communication studies, in 1962 and is still followed, influenced by and expanding into other more modern theories and disciplines. Considered as one of the oldest social science theories originated in the field of communication, it is focused on explaining how, in the course of time, an innovative idea or product, either physical or of thought, spreads through the social network, or part of it, to ultimately gain acceptance. This means that with the adoption of an innovation people start acting differently from what they have previously done due to perceiving the new product, idea or behaviour as innovative.

The pivots of the theory and the stages through which a technological innovation passes have been summed up by Clarke (1999) and Orr (2003) ${ }^{20}$ as follows:

1. knowledge (exposure to its existence, and understanding of its functions);

2. persuasion (the forming of a favourable attitude to it);

3. decision (commitment to its adoption);

4. implementation (putting it to use); and

5. confirmation (reinforcement based on positive outcomes from it).

The important characteristics of innovation or stages through which an innovation is adopted include:

1. relative advantage (the degree to which it is perceived to be better than what it replaces);

2. compatibility (consistency with existing values, past experiences and needs of potential adopters);

3. complexity (difficulty of understanding and use);

4. trialability (the degree to which it can be experimented with for a limited time);

5. observability (the visibility of its results).

The different adopter categories are identified as:

1. innovators (venturesome, individuals who want to be first to try the innovation, develop them even at the cost of taking risks);

19. More about the theory on Boston University webpage available at www. sphweb.bumc.bu.edu (accessed March 17, 2015).

20. Diffusion of Innovations, by Everett Rogers (1995) as reviewed by Greg Orr on March 18, 2003, available at https://web.stanford.edu/class/symbsys205/ Diffusion \%20of \%20Innovations.htm (accessed November 23, 2014)

Diffusion of Innovations, by Everett Rogers (1995) as reviewed by Roger Clarke, Visiting Fellow, Department of Computer Science, Australian National University, Canberra, on September 26, 1999 (accessed November 23, 2014).
2. early adopters (respectable, opinion leaders readily embracing change opportunities, already aware of needs for changes they do not need additional reflections to convince them);

3. early majority (deliberate to see first the evidence of innovation effectiveness before adopting it for themselves, rarely leaders but faster in adoption than average persons);

4. late majority (skeptical, resistive to innovation until it has been tried by the majority);

5. laggards (traditional and conservative, the hardest to convince).

In the process of adoption in the target population there are always at the extremes the groups that will readily adopt the innovation (1-2 above) and those that will try to hinder the adoption (4-5 above). So, it is of utmost importance to understand the motives setting these opponent groups on the go in specific cases. In the middle there will always be a group which will follow the more influential party.

The change agent functions are:

1. to develop a need for change on the part of the client;

2. to establish an information-exchange relationship;

3. to diagnose the client problems;

4. to create intent to change in the client;

5. to translate this intent into action;

6. to stabilise adoption and prevent discontinuance;

7. to shift the client from reliance on the change agent to self-reliance.

On the basis of this theory the implementation and diffusion of the body of phrases intended for pilotage and tug assistance, taken as innovation, will be considered.

\section{DIFFUSION OF INNOVATIONS THEORY APPLIED TO SMCP FOR PILOTAGE AND TUG ASSISTANCE}

Despite the fact that English is the occupational language in shipping and that the introduction of English into few niches devoted to the use of local languages seems to be a natural and expected course of action, there are still forces opposing it for reasons mentioned above as major. In this case, the application of Dol theory could be most helpful.

The most important element in the diffusion of English as occupational language in shipping, especially the current SMCP and their inevitable future extensions is decisiveness to diffuse them for the benefit of all the parties involved in the maritime venture or business involving speakers of different native languages as participants. This means that the IMO should recognize the importance of such initiatives as the introduction of SMCP for pilotage and tug assistance (extended version) and show commitment to their adoption worldwide. This institution is the top in the hierarchy of opinion leadership regarding all the innovations in maritime affairs, so it can initiate familiarisation 
of the parties involved with the body of phrases developed providing them with explicit reasons for the development and indicating their pragmatic function. This is the most usual method of forming favourable attitudes with prospective users, i.e. after undergoing the process of familiarisation with what one is expected to use, and after mastering the use itself and gaining thorough knowledge about the innovation, a favourable attitude is more easily formed and the innovation is more easily implemented. Of course, as soon as the first positive outcomes appear, the prospective users of innovation should be promptly and extensively informed about them.

In order for the innovation to be accepted by the prospective users, it should be compatible with the existing value system, past experiences and needs of potential adopters. In the case of SMCP extension for pilotage and tug assistance, the innovation supports the legal responsibility of a ship master in case of any incident involving his/her vessel. Thus, the consistency of the existing value system is strengthened. This can be further supported by reference to the past experiences, and in the case of the SMCP for pilotage and tug assistance there are a number of examples, in which the use of a shared working language during pilotage and tug assistance could have helped to avoid the accidents. So, this can certainly contribute to enlightening the benefits of potential adoption of innovation. Here, it is only part of future users who currently see the advantages of the adoption of innovation as the other parties in question are handicapped by individual benefits that due to their short reach obscure the more distant targets and the relative advantage of the innovation over the current practices. In view of the complexity of the ship operations to which the SMCP for pilotage and tug assistance refer, despite the advocacy of their high predictability due to mostly standard procedures followed in certain ports, and the three or more different parties involved, the phrases should be elaborate to the point of covering as many known standard procedures as possible. Therefore, a more comprehensive study of the needs of the prospective users and their contributions would certainly be welcome. The body of phrases developed should be put into use for a limited time so that the users may experiment with it. Their feedback information would contribute to the observability of the project, as it would provide the developers with the necessary hints as for the possible required corrections.

With regard to adopter categories, all ship masters would like to see this innovation implemented as soon as possible; tug masters in the area in which the development project originated are, according to freelance instructors of Maritime English providing training to towage companies, also increasingly aware of its overall advantages; only the pilots appear to be largely resistant to change of practices. Still, the change appears to make waves over time and pilots from some other ports, like the representatives of the Rotterdam pilots taking part in the
2015 G.A.M.E. seminar ${ }^{21}$, have expressed a supportive opinion to the G.A.M.E.'s project and may be viewed as prospective early adopters in terms of Dol. As regards pilots in general, it appears that, although they are normally the ones to lead, their vision is blurred by the fear of losing their unquestioned current positions in the maritime world.

Obviously, the situation calls for mediation and the Dol change agent function seems crucial. The change agent should develop the need for the change with the clients, i.e. pilots and part of tug masters, by presenting them with explicit analyses of the past ship incidents involving communication breakdowns due to use of different languages during pilotage and tug assistance operations. Often people are out of reach of other people's experiences, either due to being distant from them in place or time, or due to a lack of interest in other people's negative experiences on the grounds of believing certain things cannot happen to them, which is by all means one of the most dangerous attitudes.

G.A.M.E. participants in the 2014 summer seminar aimed at initiating the development of the need for change on the part of pilots by inviting their representatives to take part in the discussion of pros and cons of the project implementation. The participating pilots' remarks were taken into consideration and appropriate adjustments made. On this course further discussions and analyses should be undertaken in order to clarify the problems from as many different aspects as possible. Problems pointed out by the pilots or tug masters should be considered for inclusion into an extensive survey that should be administered to the two parties involved in order to enable the exchange of information among pilots in different ports as well as among pilots and tug masters. Better exchange of information should provide pilots with a sense of safety regarding different possible, but again comparatively few situations that are not in compliance with the standard procedures and are therefore not covered by the SMCP. IFSMA should insist on translating their intent into action and IMO will certainly recognize the intent as an influential contributor to the so much strived for safety at sea. Adoption of the innovation can be stabilized and its discontinuance prevented by bringing the opposing parties around an oval table for discussion on the prerequisites of the implementation of this kind of innovation. Similar changes require meticulous preparations by all the parties involved so that at a future instant in time they may confidently switch from the usage of SMCP due to IMO recommendations to its usage based on the belief in increased safety for all the participants in shipping.

In this sense, insistence on education of all the parties involved as regards linguistic skills as well as bridge team requirements doubtfully represents the course to steer.

21. 2015 G.A.M.E. one-day seminar took place in Bremen, on April 29th, 2015 at the seat of the Association. 


\section{CONCLUSION}

1. Maritime English as occupational necessity vs. cultural diversity of ships' crews

To learn a language and to use it purposefully means more than to be able to render discrete words or sentences into a different code. The contemporary society is increasingly aware of the fact that knowledge of a language represents opportunity and potential. While on one hand there is the distinct need of mastering one of the major languages in order to be able to participate in the activities they rule, on the other hand there is never more fervent striving to establish and preserve cultural differences, and preserving the language of a community is one of the most successful instruments. Crystal (2003: 191) contemplates on the future of global English as follows: "In 500 years' time, will it be the case that everyone will automatically be introduced to English as soon as they are born (or, by then, very likely, as soon as they are conceived)? If this is part of a rich multilingual experience for our future newborns, this can only be a good thing. If it is by then the only language left to be learned, it will have been the greatest intellectual disaster that the planet has ever known." Along this line of thought a conclusion can be reached that English as occupational language facilitating multiple operations in the shipping business is definitely the safest route to follow, as it has already been elaborated to high standards and maritime lecturers worldwide are continuing this work fully mindful of the underlying tradition. At the same time, the same lecturers are aware of their role as intercultural brokers ${ }^{22}$ promoting the wealth of cultural and linguistic variations outside the borders of occupational languages, but within the same human environments.

2. Maritime English as working code

Maritime English is the language used by the participants in maritime affairs in general and by those who carry out ship's business in particular. This means that the safest way to perform all kinds of ship operations is to resort to the common practice of maritime English, which should be constantly kept abreast with the introduction of new technologies into shipping business.

3. Solving issues related to the introduction of ME into few niches still ruled by local languages by way of education

The only possible way to succeed in conquering these niches, pilotage and tug assistance being such an example, is penetrating thoughtfully into the opponents' arguments. In many a case, the arguments we hear from opponents are not the actual ones, the opponents themselves often not being aware of them or not wishing to set the real arguments forth because it makes one feel vulnerable. This waypoint reached, the next to steer

22. Bocanegra-Valle, A. uses the term to refer to Maritime English lecturers as promoters of interculturality in shipping business courses. towards is education. As Tony Blair, former British PM, said in his 1997 general election speech, when referring to what would be the three main priorities for his government, the emphasis should be on "Education, education, education"! It is inarguably vital to inform all persons taking part in a common operation of the pros and cons all the participants present with regard to a change in the approach that part of the participants insist on. Enforcing a cultural change, for even in the field of an occupational language switching to new practices is always a cultural change if the professional setting is imagined as based on its specific cultural traits, is never a successful method. Educating people on the necessity of change, in this case within the occupational cultural environment, and raising the level of their awareness about other participants in the operations, as well as giving opportunity to all those involved who show readiness to neglect individual benefits in order to promote the common ones, to contribute to the project as equal and valuable collaborators is an absolute necessity.

4. Reliance on the Diffusion of innovations theory

SMCP extension for Pilotage and Tug Assistance is an innovation in the sense of occupational language extension, and its implementation and future use in the maritime business niche so far held by the local languages while pilots and tug masters of the future can rightfully be considered users of innovation in the area of the occupational working culture. Cultural changes take time to start living their best life; Diffusion of innovations theory as presented above could help in accelerating this cultural change period. In the table below the participation of all the parties involved is represented.

5. Make your opponent your promoter strategy

The current paper is also conceived of as an invitation to all the parties interested in the subject, both maritime lecturers and maritime professionals, to take part in the June 2016 G.A.M.E. summer seminar to be held in Split, Croatia where the issue will be further discussed and solutions to it sought after in order for all the parties involved to benefit from it. It is most important that the decision on the implementation be made without horizontal conflicts and implemented consciously and voluntarily to the benefit of all the on-scene subjects with positive public consequences and avoiding private ones..$^{23}$ As Meyer and Rowan (1977:343) state: "This process is most effective when norms, values, or expectations about certain forms or practices become deeply ingrained in society - institutionalized - and reflect widespread and shared understandings of social reality."

In all issues, instead of enforcing solutions or taking punitive action insisting on negotiations and argumentation is the safer course to our destination.

23. Barbara Wejnert is a professor at the University at Buffalo. Her research concerns worldwide diffusion of democracy. She has introduced the concepts of public and private consequences in the diffusion of innovations.. 
Table 1.

Parties to diffuse SMCP Pilotage and Tug Assistance extension as innovation .

IFSMA (ship masters) pilots and tug masters

- to contribute to forming

favourable attitude to innovation by informing on the current needs on the basis of examples of past negative experiences to be avoided in future by the introduction of new practice;
- pilots and tug masters in favour of changes should help raise awareness among colleagues;

- to show willingness to discuss their own and other parties' problems related to prospective new practice and suggest possible solutions:

\section{Maritime English \\ lecturers and maritime professionals in education and training}

- diffusion of knowledge through teaching, ME and training courses, - education of new generations of students aiming at developing sensitivity for requirements of other participants in joint operations

- training of actual seafarers with a view to adoption of current innovation and new future practices;

IMO

- to devise methods of forming favourable attitude to change;

- to show commitment to adoption of innovation;

- advise putting innovation to use (for a trial period);

- require feedback information from users of all parties involved on relative advantage and compatibility to stabilise adoption and prevent discontinuance.

\section{REFERENCES}

Blair, T., (2014), Tony Blair's speech, available at: http://www.youtube.com/ watch?v=2kAhChC_qxU, [accessed 22 November 2014.].

Bocanegra-Valle, A., (2015), Intercultural learners, intercultural brokers and ESP classrooms: The case of a shipping business course, Proceedings of the 32nd International Conference of the Spanish Association of Applied Linguistics (AESLA): Language Industries and Social Change, 3-5 April 2014, Seville, SPAIN, Procedia - Social and Behavioral Sciences 173 (2015), pp. 106-112. Cicero, M. T., (1918), Tusculanae Disputationes, Pohlenz, M. (ed.), Leipzig: Teubner.

Clarke, R., (1999), available at: http://www.rogerclarke.com/SOS/InnDiff.html, [accessed 17 May 2015.]

Čulić-Viskota, A., (2014), Essential English for Pilotage and Tug Assistance Proposal for SMCP Extension, Transactions on Maritime Science, 3(2), pp. 158-164., http://dx.doi.org/10.7225/toms.v03.n02.007

De Borja, M.R., (2005), Basques in the Philippines, Reno: University of Nevada Press.

Diffusion of innovations, available at: http://en.wikipedia.org/wiki/Diffusion_of_ innovations, [accessed 18 May 2015.].

Gekara, V., (2008), Globalization, State Strategies and the Shipping Labor Market, The UK's Response to Declining Seafaring Skills, PhD Thesis, Cardiff, UK: Cardiff University.

Haugh, M. and Hinze, C., (2003), A Metalinguistic Approach to Deconstructing the Concepts of 'Face' and 'Politeness' in Chinese, English and Japanese, Journal of Pragmatics, 35(10-11), pp.1581-1611, available at: http://www98.griffith.edu.au/dspace/bitstream/handle/10072/14601/33409. pdf?sequence $=1$, [accessed 26 October, 2014.].,

http://dx.doi.org/ doi:10.1016/S0378-2166(03)00049-3

Hoebel, E.A., (1954), The Law of Primitive Man: A Study in Comparative Legal Dynamics, Cambridge, MA, USA: Harvard University Press.

Ljung, M., (2010), Function Based Manning and Aspects of Flexibility, WMU Journal of Maritime Affairs 9(1), pp. 121-133.

http://dx.doi.org/10.1007/BF03195169

Magramo, M. and Gellada, L., (2009), A Noble Profession Called Seafaring: the Making of an Officer, TnasNav, The International Journal on Marine Navigation and Safety of Sea Transportation 3(4), pp. 475-480.

Merriam-Webster's Online Dictionary, for "questionnaire," available at: http://www.merriam-webster.com/dictionary/questionnaire, [accessed 21 September 2014.].

Meyer, J.W. and Rowan, B., (1977), Institutionalized Organizations: Formal Structure as Myth and Ceremony, American Journal of Sociolhy, 83, pp. 44063, in Wejnert, B., (2002) Integrating Models of Diffusion of Innovations: A Conceptual Framework, Annual Review of Sociology, (2002), 28, pp. 297-326., http://dx.doi.org/10.1146/annurev.soc.28.110601.141051

Nielsen, D., (2005), Maritime Security and MET, Malmö, Sweden:WIT Press

NYK Shipmanagement Itd., (2004), Guidelines on Intercultural Relationship.

Peabody, A. P., (1886), Cicero's Tusculan Disputations, Boston: Little \& Brown, (pp. 195-250), available at: https://archive.org/details/cicerostusculand00ciceiala, [accessed 2 September 2015.]. 
Pyne, R. and Koester, T., (2005), Methods and Means for Analysis of Crew Communication in the Maritime Domain, The Archives of Transport, 17(3-4), pp. 193-208.

Rogers, E., (2003), Diffusion of Innovations, 5th Edition, Glencoe: Simon and Schuster.

Rogers, E., (2003), Diffusion of Innovations, available at: https://web.stanford.edu/ class/symbsys205/Diffusion \%20of \%20Innovations.htm, [accessed 17 May 2015.]

Talbot, M., Atkinson, K. and Atkinson, D., (2003), Language and Power in the Modern World, Edinburgh: Edinburgh University Press.
Textbook of Maritime Medicine, Norwegian Centrefor Maritime Medicine, availableat: http://textbook.ncmm.no/component/content/article/39-6-the-sea-as-a-workingplace/760-multinational-crews-a-communication, [accessed 2 September 2015.].

The guardian, (2014), available at: http://www.theguardian.com/politics/2007/ apr/26/tonyblair.labour, [accessed 22 November 2014.].

Wejnert, B., (2002), Integrating Models of Diffusion of Innovations: A Conceptual Framework, Annual Review of Sociology, 28, pp.297-326., available at: http://www.wejnert.com/files/out2.pdf, [accessed 18 May 2015.]., http://dx.doi.org/10.1146/annurev.soc.28.110601.141051 